\title{
Utilização do playground por crianças com paralisia cerebral tipo diparética espástica: preferências e dificuldades relatadas pelas mães
}

\section{Utilization of playground by children suffering from cerebral palsy, spastic diparetic type: preferences and difficulties reported by mothers}

\author{
Ana Paola Sarpi Chiodo Soler ${ }^{1}$, Luciana Krauss Rezende ${ }^{2}$, \\ Silvana Maria Blascovi-Assis ${ }^{3}$
}

\begin{abstract}
SOLER, A. P. S. C.; REZENDE, L. K.; BLASCOVI-ASSIS, S. M. Utilização do playground por crianças com paralisia cerebral tipo diparética espástica: preferências e dificuldades relatadas pelas mães. Rev. Ter. Ocup. Univ. São Paulo, v. 22, n. 1, p. 19-26, jan./abr. 2011.

RESUMO: Este estudo teve como objetivo investigar como ocorre a utilização do playground por um grupo de crianças com paralisia cerebral tipo diparética espástica segundo relato verbal de suas mães. Participaram da pesquisa dez mães de crianças entre quatro e oito anos, para as quais foi aplicado um questionário contendo perguntas sobre a utilização desse espaço pela criança. Posteriormente foram selecionadas cinco mães, que preenchiam os critérios estabelecidos para o estudo, que era freqüentar o playground regularmente com seu filho. Foi agendada uma entrevista semi-estruturada, realizada pela pesquisadora e gravada em fita cassete. As mães relataram freqüentar playgrounds de parques públicos com seus filhos, ressaltando que as crianças reagiam bem aos estímulos oferecidos pelos brinquedos, apresentando pouca dificuldade nos relacionamentos sociais. Referiram também ter sido pouco orientadas sobre os benefícios do playground por profissionais que atuam na área do desenvolvimento. $\mathrm{O}$ desempenho das crianças mostrou que este ambiente pode ser favorável ao desenvolvimento motor e social, proporcionando os estímulos vestibulares, proprioceptivos e táteis, semelhantes àqueles oferecidos na terapia de integração sensorial. Esperase apontar uma nova alternativa de estimulação para a criança com paralisia cerebral no ambiente natural do playground, proporcionando melhor desenvolvimento motor, cognitivo e social.
\end{abstract}

DESCRITORES: Paralisia cerebral; Desenvolvimento infantil; Atividades de lazer; Jogos e brinquedos; Criança.

\footnotetext{
1 Fisioterapeuta, Mestre em Distúrbios do Desenvolvimento pela Universidade Presbiteriana Mackenzie, Docente do Curso de Fisioterapia da Universidade Presbiteriana Mackenzie.

2. Fisioterapeuta, Doutoranda em Distúrbios do Desenvolvimento pela Universidade Presbiteriana Mackenzie, Bolsista CAPES.

3. Fisioterapeuta, Docente do Programa de Pós-graduação em Distúrbios do Desenvolvimento pela Universidade Presbiteriana Mackenzie.
}

Endereço para correspondência: Ana Paola Sarpi Quiodo Soler. Alameda Jaú, 600 ap 21 Jardim Paulista. CEP: 01420-000. São Paulo. e-mail: quipaola@uol.com.br 


\section{INTRODUÇÃO}

$\mathrm{P}$ iovesana (1998, p. 9), descreve a paralisia cerebral (PC) como "um grupo não progressivo, mas freqüentemente mutável, de distúrbio motor (tônus e postura), secundário a lesão do cérebro em desenvolvimento, onde o efeito lesivo pode ocorrer no periodo pré, peri ou pós-natal".

Sabe-se que a criança com disfunção motora apresenta limitação para explorar o ambiente, o que acarretará déficit na exploração sensorial provocando alterações nas áreas perceptual e cognitiva. Essas alterações podem comprometer o desenvolvimento da criança, que pode ser confundido com retardo mental, mascarando as possibilidades cognitivas das mesmas (BRUCK et al., 2001).

A classificação topográfica da PC define que as crianças com diparesia espástica apresentam comprometimento motor principalmente em membros inferiores e geralmente apresentam-se em classificações funcionais de leve a moderada (PFEIFER et al., 2009). Entretanto, esta criança com disfunção motora apresenta também limitação para explorar o ambiente, acarretando déficits em seu desenvolvimento. Poderá também, interferir na linguagem e no comportamento, mostrando uma importante relação entre a função motora e as outras funções. Fatores ambientais e culturais reforçam o atraso da criança com PC (GUSMAN, 1998; LORENZINI, 1999).

O tratamento dessas crianças tem como objetivo básico levar ao Sistema Nervoso Central a maior quantidade de informações sensoriais, exteroceptivas e proprioceptivas possíveis. Acredita-se também que quanto mais precoce for esta intervenção, ocorrerá maior possibilidade de inibição dos padrões anormais, proporcionando à criança afetada melhor evolução e desempenho funcional (BOBATH, 1978; FINNIE, 2000; GUSMAN, 1998).

A teoria da Integração Sensorial focaliza-se nos sistemas vestibular, proprioceptivo, tátil, auditivo, visual, olfativo e gustativo. É o processo pelo qual o cérebro organiza as informações, de modo a dar uma resposta adaptativa adequada organizando as sensações do próprio corpo e do ambiente (LAMPERT, 1999; VARELA, 2003).

Este tipo de terapia veio acrescentar aos métodos tradicionais uma nova forma de estimulação às crianças com deficiência, onde o aspecto lúdico também é valorizado, podendo ser realizada juntamente com a terapia convencional (SCHAAF; MILLER, 2005). Estudos sobre o brincar da criança com PC vem sendo ampliados, uma vez que este a partir desta atividade é possível ampliar as possibilidades de avaliação e estimulação da criança (SANT'ANNA et al., 2008)

O sistema neuropsicomotor tem como tarefa fundamental a transformação de uma idéia em movimento. Segundo Lorenzini (1999) a motricidade não é somente o movimento, mas também a energia que o produz, ou seja, o que gerou o movimento.

Dessa forma, para cada informação sensorial recebida pelo cérebro, o sistema nervoso tentará produzir uma resposta, provocando o aprendizado motor e cognitivo.

É a partir do brincar que a criança expressa os movimentos que aprendeu, interage com o brinquedo desenvolvendo aspectos cognitivos e emocionais. Também passa a interagir com o mundo, a partir de relações vinculares que estabelece com a realidade externa (KUDO, 1994; LOPES, 2003).

O papel da família, geralmente representado pela mãe, por ser a maior cuidadora, é fundamental. Um ambiente favorável, juntamente com uma atuação calorosa e afetiva, faz a diferença. Permitir que a mãe compartilhe com a criança momentos de prazer, através da brincadeira, intensifica o vínculo mãe-filho; e contribui para o aprendizado da criança (LORENZINI, 1999; RANGEL, 2003).

Deve-se, portanto, questionar até que ponto os tratamentos oferecidos à criança com $\mathrm{PC}$ buscam a recuperação máxima das limitações visando à produção na vida adulta. Quanto será que é furtado da criança com deficiência a possibilidade de manifestação do elemento lúdico em seu dia-a-dia? Buscar alternativas terapêuticas que valorizem esse aspecto pode ser um caminho de estimulação prazerosa e de respeito à criança e à sua família.

O termo playground foi escolhido para este trabalho tendo como base a nomenclatura utilizada pela ABNT Associação Brasileira de Normas Técnicas, que publicou normas para garantir a segurança nos equipamentos de playgrounds em 1999, baseando-se nas normas inglesas uma das mais rígidas do mundo, resultando em uma cartilha que indica como deve ser um playground (LINDNER, 2000). A maioria dos brinquedos encontrados nos playgrounds não tem dispositivos de segurança, sendo que muitas vezes até mesmo crianças normais acabam sofrendo acidentes. ANBR 14350-1 trata dos requisitos e métodos de ensaio e a NBR 14350-2 trata das diretrizes para elaboração de contrato para aquisição/fornecimento de equipamentos de playground (LAUFER, 2001).

A criança pequena que brinca em casa com seus pais cresce e começa a desenvolver a sua sociabilização, interagindo com outras crianças inicialmente em playgrounds, festas e passeios. Muitas vezes é no playground que elas trocam experiências adquiridas anteriormente, exercitam 
habilidades motoras e se relacionam entre si. A criança precisa adaptar seu comportamento para interagir e isso leva a um amadurecimento emocional (RODRIGUES; MIRANDA, 2001).

Para a criança com PC, foco deste estudo, considerase importante a oportunidade de brincar no playground, mesmo que necessite de algumas adaptações para a utilização dos brinquedos, dependendo do comprometimento motor que apresente, já que esta é uma rica estimulação para o seu desenvolvimento.

A presença da mãe ou de um cuidador faz-se necessária para que a criança possa realmente explorar o ambiente. A família, no entanto, deve receber orientações sobre como lidar com seu filho deficiente conseguindo assim, assumir sua parte na tarefa social, de proporcionar lazer e integração do seu filho (BLASCOVI-ASSIS, 2009a).

Portanto, o playground pode ser considerado uma área privilegiada onde é possível realizar a estimulação da criança de forma lúdica preservando a naturalidade do ambiente e é então "um espaço alternativo rico em estímulos para o exercício do equilíbrio corporal, além de ser propício para os contatos sociais" (BLASCOVI-ASSIS, 2009b, p. 67).

Este trabalho teve como objetivo investigar como ocorre a utilização do playground pela criança com paralisia cerebral tipo diparética espástica segundo relato verbal de suas mães e conhecer a opinião da própria criança sobre o playground.

\section{PROCEDIMENTOS METODOLÓGICOS}

Richardson (1999, p. 22) define método como "o caminho ou a maneira para chegar a determinado fim ou objetivo". Desta forma, para esclarecer o objetivo deste trabalho, optou-se por um enfoque qualitativo, permitindo assim, aprofundar o conhecimento do problema proposto.

Participaram do estudo dez mães de crianças com diagnóstico de PC diparéticas espásticas, entre quatro e sete anos de idade, que atualmente são atendidas pela fisioterapia numa clínica escola em uma universidade na cidade de São Paulo. Estas responderam a um questionário sobre a utilização do playground no cotidiano de seus filhos. Foram incluídas crianças que já haviam adquirido a postura sentada sem apoio, apresentando bom controle de tronco, com bom desenvolvimento cognitivo e que conseguissem se expressar verbalmente. Foram excluídas aquelas que apresentassem deficiência sensorial, como déficit visual e/ou auditivo, crises convulsivas ou outras síndromes associadas.

Posteriormente foram selecionadas através de sorteio, cinco crianças e suas respectivas mães para participação de uma entrevista a partir de um roteiro de perguntas pré-elaborado para as mães. As entrevistas foram realizadas individualmente e gravadas, com a autorização das participantes em horário pré-agendado. As participantes receberam uma Carta de Informação para participação em cada fase da pesquisa e assinaram o Termo de Consentimento Livre e Esclarecido. O projeto teve aprovação do comitê de Ética em Pesquisa da Universidade Presbiteriana Mackenzie sob parecer n. 861/05/05. As fitas foram transcritas na íntegra para que o seu conteúdo pudesse ser analisado.

\section{RESULTADOS E DISCUSSÃO}

As crianças participantes do estudo eram de ambos os sexos, sendo seis do sexo feminino e quatro do sexo masculino. Três apresentavam-se independentes para a marcha, quatro realizavam a marcha com auxílio de terceiros e três faziam uso de cadeira de rodas.

Todos os questionários foram respondidos por mães das crianças, sendo que apenas uma mãe, relatou que não costuma levar o filho regularmente ao playground por ele demonstrar medo.

Quando questionadas sobre a freqüência no playground, sete responderam que levam a criança pelo menos uma vez por semana; as demais levavam em freqüência não regular.

Nove mães relataram que seus filhos gostam dos brinquedos do playground, e entre os brinquedos, também escolheram mais do que uma opção, sendo o balanço o brinquedo preferido, seguido do gira-gira, escorregador, ponte suspensa, tanque de areia e carrossel. Apenas uma mãe relatou que a criança não gosta dos brinquedos. $\mathrm{O}$ tanque de areia como foi citado por nove mães, que relataram que a criança gosta de brincar na areia.

As dificuldades em freqüentar o playground apareceram para situações como a distância da própria casa, dificuldade de transporte, existência de brinquedos só para crianças grandes, brinquedos em mau estado de conservação, dificuldades em posicionar a criança nos brinquedos. A rejeição da criança com PC por outras crianças também foi mencionada.

As 10 mães relataram que nunca foram orientadas por nenhum profissional sobre a importância do playground no cotidiano dos seus filhos, e que gostam de levar a criança no playground.

Na segunda fase do estudo, foram contatadas as sete mães que freqüentavam pelo menos uma vez o playground com seus filhos. Foram sorteadas cinco para agendamento da entrevista semi-estruturada. A entrevista foi realizada individualmente, em ambiente tranqüilo e gravadas em 
gravador de voz para posterior transcrição na íntegra. A partir das transcrições, foram elaboradas categorias para análise dos dados. As categorias de análise foram: a) características do playground; b) reação da criança aos brinquedos do playground; c) dificuldades encontradas; d) relacionamentos sociais; e) significado de brincar no playground.

\section{Categoria 1: características do playground}

A maioria das mães relatou que o playground onde costumavam levar seus filhos tinha como brinquedos disponíveis balanço, escorregador, gangorra, ponte suspensa e tanque de areia.

"tem bastante brinquedo, tem balanço, gangorra, tanque de areia... tem escorregador, só" (M1).

"tem balanço, tem tudo lá. Tem escorregador, tem gira-gira, tanque de areia" (M2).

Blascovi-Assis (2009b) constatou que esses brinquedos também eram os mais comuns em playgrounds públicos; a mesma autora, em 1994, já ressaltava a importância do tanque de areia e dos brinquedos para o desenvolvimento da criança, apontando possibilidades de aprimoramento da coordenação motora, do equilíbrio, do esquema corporal, da orientação espacial e da sensibilidade.

M4 prefere levar a criança em parque de diversões fechado (particular), com brinquedos eletrônicos, como carrossel, trenzinho, por acreditar ser mais seguro para a criança.

"tem brinquedos montados, ela fica a vontade, é tipo brinquedo de circo de antigamente, tem bastante coisa, trenzinho... tem segurança, tem uma moça lá em cada brinquedo (...) se tem cinto para prender, tudo bem" (M4).

Essa mãe demonstra sentir-se segura com a presença de monitores que auxiliam no cuidado com o seu filho.

Laufer (2001) já considerava que a maioria dos brinquedos encontrados nos playgrounds não tem dispositivos de segurança, sendo que os acidentes podem acontecer com qualquer criança.

M1 relata que "não tem segurança, só a gente mesmo prá ficar perto cuidando, não tem ninguém assim prá ficar olhando". Observa-se também nesta fala, a existência de uma expectativa de auxílio ao cuidado da criança em situações de playground. Em 1999 a ABNT publicou normas específicas para a segurança de equipamentos de playground, mas nem sempre as normas vem sendo cumpridas (LAUFER, 2001).

Das mães entrevistadas, quatro referiram levar seus filhos em playgrounds públicos e disseram ser um local agradável e gostoso, com árvores e alguma vegetação. Apenas M4 prefere freqüentar um local fechado, tipo parque de diversões particular por achar mais seguro.

\section{Categoria 2: reação da criança aos brinquedos do playground}

Todas as crianças, de acordo com a percepção das entrevistadas, gostam muito dos brinquedos, e as mães relatam que elas escolhem onde querem ir. Algumas, pela facilidade de locomoção, ficam mais à vontade para utilizar todos os brinquedos disponíveis. Outras, que precisam de mais ajuda, solicitam o auxílio da mãe e quando estão posicionados, se divertem bastante.

"ele gosta muito do tanque de areia e do balanço, vai direto, sempre ele vai..." (M1).

"ele não gosta muito da grama, aí ele fica só no mesmo brinquedo..." (M2).

De acordo com a pesquisa de Lampert (1999), o estímulo oferecido pelos brinquedos do playground vai ao encontro dos princípios da terapia de Integração Sensorial, que prioriza o uso de equipamentos suspensos como balanços, redes, plataformas entre outros, enriquecidos por texturas diferentes, para proporcionar à criança estimulação vestibular, tátil e proprioceptiva.

\section{Categoria 3: dificuldades encontradas}

As mães relataram dificuldade de transporte, da distância até o playground e para mudar a criança de brinquedo, devido ao peso e a necessidade de carregá-la. Ainda assim, a maioria relata tranqüilidade e diz estar acostumada em levar o filho para brincar.

"só para levar de ônibus porque ele enjoa, passa mal.... mas o resto não tem dificuldade... é fácil" (M2)

"ah... assim, só na hora de carregar de colocar assim no brinquedo...na hora e mudar de brinquedo...fica um pouquinho mais pesado...mas já tô acostumada" (M3)

Em relação às dificuldades apresentadas pelas 
crianças, as mães se referem principalmente à necessidade de participação da mãe para auxiliar a criança a usar o brinquedo.

"vai em todos os brinquedos, às vezes precisa de ajuda, eu vou com ele, ele pede, ele senta, eu jogo, ele começa a gritar, aí volto de novo ...ele fica feliz" (M2)

" outras crianças perguntam se pode girar forte, o duro é que eu tinha que ficá, com medo dele ficar sozinho...tinha que ficar correndo junto com ele para segurar" (M3)

\section{Categoria 4: relacionamentos sociais}

As opiniões das mães foram divergentes, três acharam que a criança se relaciona normalmente com as outras crianças do playground e duas, que ocorrem diferenças.

" normal...ela se sente uma criança normal, igual as outras...ainda bem" (M2).

" nesses brinquedos vai duas crianças, ela vai conversando com a coleguinha do lado" (M4)

De acordo com a literatura, através do brincar a criança passa a interagir com o mundo a partir de relações vinculares que estabelece com a realidade externa (KUDO, 1994; LOPES, 2003 ).

Nestas falas, percebe-se que as dificuldades para inclusão social podem ocorrer em qualquer ambiente por razões diversas, incluindo a falta de informação. A iniciativa de participação dessa criança em brincadeiras no ambiente natural pode proporcionar melhor oportunidade de desenvolvimento motor, cognitivo e social. De acordo com Mazzotta (2006) é fundamental que a acessibilidade seja interpretada como elemento indispensável para a inclusão social de todas as pessoas nos diferentes espaços da vida pública ou privada. Para o autor, "não é concebivel, pois, defender inclusão social abstraindo-se as condições básicas de acessibilidade nos espaços sociais públicos ou que são compartilhados por todos". Ressalta ainda que quando encontramos obstáculos ao acesso aos bens e serviços sociais e culturais isso priva a liberdade e a eqüidade nas relações sociais fundamentais à condição de ser humano. Acessibilidade não é só a possibilidade de entrar em um ambiente, mas é um direito de participação ativa no meio social, é cidadania e inclusão social.

As mães relataram também sobre o relacionamento social do seu filho deficiente com os adultos, que demonstraram curiosidade em relação à criança. Isto parece ser bem administrado pelas mães, embora se sintam um tanto constrangidas.

"às vezes, a gente pára no farol e todo mundo fala porque eu tô com ele no colo, com uma criança tão grande" (M2)

"às vezes, tem gente que pergunta..ah! ele não anda ...porquê? aí eu falo que faltou oxigênio na hora do parto... aí a pessoa fala assim, nossa mas ele é esperto e pronto" (M3)

\section{Categoria 5: significado de brincar no playground}

Todas as mães relataram gostar de brincar no playground com as crianças.

“... prá mim é legal, eu gosto de brincar com ele" (M1).

“... é muito importante prá mim” (M2).

De acordo com Lorenzini (1999), a família participativa interfere na evolução nos aspectos motor, cognitivo, sensorial, afetivo e sócio cultural, e a presença da mãe contribui muito para a evolução da criança. BlascoviAssis (2009a) chama a atenção para a importância da relação natural entre mãe e filho com deficiência, e sugere que a participação da família no desenvolvimento da criança deva acontecer em ambientes prazerosos e situações de lazer.

\section{Categoria 6: orientações recebidas}

Quando as mães foram abordadas de forma objetiva na primeira fase da pesquisa sobre a possível orientação recebida de algum profissional referente à importância do playground para seus filhos, todas disseram que não receberam qualquer informação sobre os benefícios e oportunidades de desenvolvimento neste espaço.

Já nesta segunda fase, três mães disseram nunca terem sido orientadas, enquanto uma (M5) já havia recebido orientação quanto ao tanque de areia e uma (M2) foi orientada por uma fisioterapeuta sobre a utilização do playground para o desenvolvimento da criança. De um modo geral considerando-se tanto as informações obtidas nos questionários como nas entrevistas, as orientações sobre os benefícios sociais e de desempenho que podem ser obtidos a partir da freqüência no playground são pouco enfatizadas pelos profissionais que atuam na área do desenvolvimento. 
O papel da orientação é mostrar às famílias oportunidades que facilitem o desenvolvimento da criança, especialmente aquelas que podem estar favorecendo a interação entre a mesma e sua família de modo prazeroso; neste caso, o ambiente natural do playground pode auxiliar este processo.

A semelhança dos brinquedos do playground com os equipamentos da sala de Integração Sensorial pode criar uma nova alternativa de estimulação para a criança com paralisa cerebral, sendo a presença da família de fundamental importância.

Como o comprometimento motor do PC diparético espástico é mais evidenciado em membros inferiores, segundo definido por Bobath (1990), observa-se em quase todas as atividades, maior facilidade das crianças em se segurar com as mãos nos brinquedos, manter bom controle de tronco sentado e pouca movimentação ativa em membros inferiores. Fica claro que o comprometimento motor é variável dentro do mesmo tipo de paralisia cerebral, portanto, as crianças com marcha independente ou com auxílio tiveram mais autonomia e melhor desempenho motor no playground.

A interação entre as crianças foi pobre mostrando a dificuldade de aproximação da criança deficiente e das demais que estavam brincando. A presença da mãe foi fundamental para a exploração dos brinquedos. BlascoviAssis (2003) reforça a idéia de que a família precisa ser orientada em como participar com seu filho deficiente em atividades de lazer, visando à integração social do mesmo.

De acordo com as mães, as preferências das crianças estão no balanço e na casinha de madeira com escada de cordas. De acordo com Blascovi-Assis (2009b) e Laufer (2001), o balanço é o brinquedo preferido das crianças, mesmo necessitando de um adulto para brincar, e estimula o sistema vestibular, desenvolvendo equilíbrio e coordenação motora. A casinha de madeira desenvolve equilíbrio, criatividade e interação social das crianças. A areia é um material bastante rico em estímulos táteis. Esta estimulação corresponde aos princípios da Integração Sensorial descrito por Ayres (1995).

O prazer demonstrado pelas cinco crianças em brincar no playground reforça a importância do lúdico para a vida humana, contribuindo para o processo terapêutico sendo o ambiente fundamental para este desenvolvimento (SANTOS, 2001). De acordo com Finnie (2000); Lorenzini (1999) e Rodrigues e Miranda (2001), devemos dar oportunidade para a criança deficiente brincar, levando a brincadeira até ela e auxiliando na exploração do brinquedo e do ambiente.
A primeira pergunta realizada na entrevista foi referente à idade em que a criança começou a freqüentar o playground. Todas as mães responderam que desde a fase entre 18 e 24 meses já levavam seus filhos para brincar. Este dado sugere que a criança com PC diparética espástica apresenta um desempenho motor favorável ao uso dos brinquedos do playground, já que o seu desenvolvimento fica comprometido de modo mais grave nos membros inferiores. Nesta fase, a criança pode apresentar alterações motoras, mas pode também demonstrar bom controle de cabeça e de tronco (BOBATH, 1990).

\section{CONCLUSÃO}

A criança com paralisia cerebral tipo diparética espástica apresenta um desempenho motor favorável ao uso dos brinquedos do playground, já que o seu comprometimento motor é mais acentuado nos membros inferiores, o que permite manter um bom controle de tronco se segurando com as mãos e usufruir do estímulo que o brinquedo oferece.

As mães entrevistadas relataram que as crianças reagem bem, demonstrando prazer aos movimentos oferecidos pelos brinquedos do playground, o que é semelhante aos princípios da terapia de Integração Sensorial que enfatiza o uso de equipamentos suspensos para a estimulação de crianças com paralisia cerebral.

As orientações familiares sobre os benefícios sociais e de desempenho que o playground pode oferecer são pouco enfatizadas pelos profissionais que atuam com a criança com PC, sendo este um campo a ser explorado.

A inclusão da criança com PC no ambiente do playground ainda é pouco observada, não sendo freqüentes os estudos que exploram essa temática, seja no aspecto da inclusão social pelo lazer ou pelas possibilidades de desenvolvimento que essa situação oferece enquanto forma alternativa de estimulação.

A participação da família é de fundamental importância para a criança deficiente, encorajando-a no desenvolvimento de seu potencial. Especialmente em ambiente natural, a relação família-criança fica preservada, sendo um momento de prazer para ambos. Novas pesquisas devem ser realizadas já que a literatura sobre o brincar da criança deficiente no playground é bastante escassa.

A alternativa de utilizar o playground como ambiente estimulador oferece à criança com paralisia cerebral oportunidade de explorar o ambiente e testar seus limites, exercitar o corpo e a mente junto com outras crianças, enriquecendo sua vida cotidiana e vivenciando novas perspectivas de humanização em suas relações sociais. 
SOLER, A. P. S. C.; REZENDE, L. K.; BLASCOVI-ASSIS, S. M. Utilization of playground by children suffering from cerebral palsy, spastic diparetic type: preferences and difficulties reported by mothers. Rev. Ter. Ocup. Univ. São Paulo, v. 22, n. 1, p. 19-26, jan./abr. 2011.

\begin{abstract}
The aim of this study was to investigate how does the use of the playground by a group of children with spastic diparetic cerebral palsy, according to their mothers' verbal report. Ten mothers of children between four and eight years participated of this research and answered a questionnaire with questions about the child performance in the playground space. Subsequently, five mothers were selected to participate in another phase of the study, which consisted in regularly attend the playground with their children. The data was collected in a semi-structured interview, conducted by the researcher and recorded on audiotape. Mothers reported frequenting public parks with playgrounds for their children, stating that the children reacted well to the stimuli offered by the toys, presenting little difficulty in social relationships and refer that they have been little counseling on the benefits of the playground by professionals who working in development. Children's performance showed that this environment may be conducive to the motor and social development, providing the vestibular, proprioceptive and tactile stimulus, like those offered on sensory integration therapy. It is hoped an alternative propose of stimulation for the child with cerebral palsy in the natural environment of the playground, providing a better motor development, cognitive and social development.
\end{abstract}

KEY WORDS: Cerebral palsy; Child development; Leisure activities; Play and playthings; Child.

\title{
REFERÊNCIAS
}

AYRES, A. J. Sensory integration and the child. 20. ed. Los Angeles, California: Western Phycological Services, 1995.

BLASCOVI-ASSIS, S. M. Tanque de areia: um espaço alternativo para a estimulação de crianças com síndrome de Down. Temas sobre Desenvolvimento, São Paulo, v. 4, n. 20, p. 28-32, 1994.

BLASCOVI-ASSIS, S. M. Lazer para deficientes mentais. In: MARCELLINO, N. C. (Org.). Lúdico, educação e educação física. 3. ed. Ijuí, RS: Ijuí, 2009a.

BLASCOVI-ASSIS, S. M. Lazer e deficiência mental: o papel da família e da escola em uma proposta de educação pelo e para o lazer. $3^{\text {a }}$. Ed. Campinas, SP: Papirus, 2009b.

BOBATH, B.; BOBATH, K. Desenvolvimento motor nos diferentes tipos de paralisia cerebral. São Paulo: Manole, 1978.

BOBATH, K. Uma base neurofisiológica para o tratamento da paralisia cerebral. 2. ed. São Paulo: Manole, 1990. 110p.

BRUCK, I.; ANTONIUK, S. A.; SPESSOTTO, A.; BEM, R. S.; HAUSBERGER, R.; PACHECO, C. G. Epilepsy in children with cerebral palsy. Arquivos Neuro-Psiquiatria, São Paulo, v. 59, n. 1, p. 35-39, 2001.

FINNIE, N. O manuseio em casa da criança com paralisia cerebral. 3. ed. São Paulo: Manole, 2000.

GUSMAN, S.; TORRE, C. A. Fisioterapia em paralisia cerebral. In: SOUZA, A. M. C.; FERRARETO, I. Paralisia cerebral: aspectos práticos. São Paulo: Memnon, 1998. p. 169-206.

KUDO, M. A. Fisioterapia, fonoaudiologia e terapia ocupacional em Pediatria. 2. ed. São Paulo: Sarvier, 1994.

LAMPERT, R. Modelo de integração sensorial. Reabilitar, São Paulo, n. 4, p. 16-23, 1999.

LAUFER, A. M. Recomendações para projeto de brinquedos de recreação e lazer adaptados à criança com paralisia cerebral. 2001. Dissertação (Mestrado em Gestão do Design e do Produto), Universidade Tuiuti, Curitiba, Paraná, 2001.

LINDNER, G. Parquinho de diversões não é brincadeira. $A$ Noticia - AN Cidade, 2000. Disponível em: [http: /www.an.uol. com.br/2000/br/09/cod.htm]. Acesso em 11 jan 2005.

LORENZINI, M. V. Brincando no ambiente natural: uma contribuição para o desenvolvimento sensório-motor da criança portadora de paralisia cerebral. 1999. Tese (Doutorado em Educação Física) - Universidade Estadual de Campinas, São Paulo, 1999.

MAZZOTTA, M.J.S. Acessibilidade e a indignação por sua falta. In: I CONFERÊNCIA NACIONAL DOS DIREITOS DA PESSOA COM DEFICIÊNCIA, 8., 2006, Brasília. Caderno de Textos. Brasília: Secretaria Especial dos Direitos Humanos, SEDH/ CONADE - CORDE, 2006 ${ }^{\mathrm{a}}$. P.30-32.

PFEIFER L. I.; SILVA, D. B. R.; FUNAYAMA, C.A. R.; SANTOS, J. L. Classificação da paralisia cerebral: associação entre gênero, 
idade, tipo motor, topografia e Função Motora Grossa. Arquivos de Neuro-Psiquiatria, v. 67, n. 4, p. 1057-1061, 2009.

PIOVESANA, A. M. S. G. Paralisia cerebral: contribuição do estudo por imagem. In: SOUZA, A. M. C.; FERRARETO, I. Paralisia cerebral: aspectos práticos. São Paulo: Memnon, 1998. p. 8-32.

RANGEL, M. O. O recurso terapêutico do brincar: subsídios para a formação do fisioterapeuta. Dissertação (Mestrado em Educação) - Faculdade de Educação, Universidade Cidade de São Paulo, São Paulo, 2003.

RICHARDSON, R.J. Pesquisa social: métodos e técnicas. 3.ed. São Paulo: Atlas, 1999.

RODRIGUES, M. F.; MIRANDA, S. M. A estimulação da criança especial em casa: entenda o que acontece no sistema nervoso da

Recebido para publicação: 11/02/11

Aceito para publicação: 29/03/11 criança deficiente e como você pode atuar sobre ele. São Paulo: Atheneu, 2001.

SANT'ANNA, M. M. M.; BLASCOVI-ASSIS, S. M.; MAGALHÃES, L. C. Adaptação transcultural dos protocolos de avaliação do Modelo Lúdico. Revista de Terapia Ocupacional da Universidade de São Paulo, v. 19, n. 1, p. 34-47, 2008.

SANTOS, S. M. P. (Org.). A ludicidade como ciência. Petrópolis, RJ: Vozes, 2001.

SCHAAF, R. C.; MILLER, L. J. Occupational therapy using a sensory integrative approach for children with developmental disabilities. Mental Retardation Developmental Disbilities Research Reviews, v. 11, n. 2, p. 143-148, 2005.

VARELA, V. Integración sensorial. Pediatria al Dia, Santiago, Chile, v. 1, n. 19, p. 40-43, 2003. 